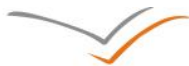

\title{
VERSITA
}

\section{Academic Mobility in the Western Balkans}

\author{
Jasna Bošnjović \\ University of Sarajevo, Sarajevo, Bosnia and Herzegovina \\ Veljko Trivun
}

University of Sarajevo, School of Economics and Business, Sarajevo, Bosnia and Herzegovina

\begin{abstract}
Background: With the aim of encouraging mobility between higher education institutions in the Western Balkan countries and those in the European Union (EU), the European Commission initiated a series of measures to increase the share of students primarily from the Western Balkans who spend at least one semester away from their home institutions, but also the share of young people from EU member states who come to Western Balkan (WB) countries. Objectives: Aim of the paper is to determine the degree of representation of internationalisation strategy and policy elements in the internal documents of higher education institutions and its direct impact on the development of mobility. Methods/Approach: An electronic survey has been created and sent to representatives of 9 EU and 11 WB universities. Respondents were mainly international relations officers or management representatives. Mann-Whitney test was applied in order to test differences between EU and WB universities. Results: The conducted Mann-Whitney nonparametric tests show that the degree of representation of internationalisation strategy and policy elements in the internal documents of a higher education institution has a direct impact on the development of mobility. Conclusions: By 2020, the European Commission aims to have $20 \%$ of all students acquiring an academic degree within the European Higher Education Area participate in mobility. This paper sheds light on this segment and indicates possible directions for actions aimed at developing mobility at institutions in Western Balkan countries.
\end{abstract}

Keywords: Mobility, European Higher Education Area, organisational structure, higher education institutions, Western Balkans, European Union

JEL classification: 123

Paper type: Research article

Received: 8, November, 2012

Revised: 4, March, 2013

Accepted: 6, April, 2013

Citation: Bošnjović, J., Trivun, V. (2013). "Academic Mobility in the Western Balkans", Business Systems Research, Vol. 4, No. 1, pp. 76-86.

DOI: 10.2478/bsrj-2013-0007

\section{Introduction}

Debates on higher education both within countries and at the international level are part of numerous social and economic analyses. The internationalisation of higher education has become central to debates after 1990 (Teichler, 2012). Within internationalisation, student mobility ranks high on the list of priorities. The first programme that included financial incentives for academic community mobility was the Fulbright programme founded in 1948, after World War II, a time marked by hatred, killing and even genocide. In such circumstances, mobility was expected to widen educational and professional capacity, but also to be a counterweight to hatred and distrust - to contribute to the spread of a cosmopolitan attitude and strengthen mutual understanding between countries. Since the 1970s, the European Community has been the most active European factor stimulating crossborder student mobility. Already at that time, the emphasis was on exposing students to other 
educational systems in order to encourage and develop the cultural diversity of Europe. At the same time, student mobility can also be a means of developing or changing the culture and patterns of behaviour established in individual academic environments. For example, various programmes for encouraging mobility were developed in the hope of changing attitudes to facilitate growing global understanding, more positive views of partner countries, strengthening empathy towards other cultures. Institutionally, mobility contributes to building capacities by exposing the work process to persons from different environments (foreign students), and the inevitable feedback effect of domestic students participating in mobility in the work of institutions, both those they came from and those that hosted them abroad.

This paper aims to explore the influence of this new type of structured mobility on the institutions participating in a mobility programmes, not only in terms of research and teaching structures, but also in terms of support processes, and to provide an insight into the capacities of higher education systems of Western Balkan countries compared to those of EU member states when it comes to managing mobility as one of the strategic priorities for the creation of the European Higher Education Area.

Higher education systems differ between institutions and between countries. Due to the complex technology of the process of mobility and the diverse activities that make up this process, mobility is a fitting segment of higher education for exploring structural capacities of higher education institutions in Western Balkan countries and comparing them to the functioning of this same segment at institutions in EU member states.

The hypothesis of this research is that the degree of representation of internationalisation strategy and policy elements in the internal documents of a higher education institution has a direct impact on the development of mobility. Accordingly, (1) the degree of representation of internationalisation strategy and policy elements in the internal documents of a higher education institution is measured by the existence of Rules on Mobility within the institution, and (2) the development of mobility is measured by the proportion of visiting students and departing students in the total number of students expressed as percentage values.

\section{Literature review}

\section{Academic mobility}

Defining academic mobility is a key issue for understanding what mobility entails. Defining and categorising this term often leaves potential members outside the group. According to De Wit (2012), there are four basic definitions whose categories cover the greatest number of students:

1. Students who go abroad for 3-12 months as part of their home study to earn credits for their home degree: exchange students, international internships, (inter)national scholarship programme students (Fulbright, ERASMUS, etc.). This type of mobility is called temporary mobility, but the term credit mobility is more appropriate.

2. Students who go abroad for an undergraduate or graduate degree, pursuing the degree programme completely or mostly at the foreign host institution, with private funding, with (inter)national scholarships, or with income from work during the period of study. These students are found in most of the (inter)national statistics. They are mostly referred to as diploma or degree mobility students.

3. Students who follow a completely or mostly undergraduate or graduate degree programmes in their own country which are delivered by foreign providers, virtually or otherwise. These students in most cases are excluded from the statistics.

4. Students who follow a completely or mostly undergraduate or graduate degree programmes on the basis of a joint or double degree between a foreign or national provider. They sometimes appear in the statistics under the label "temporary", sometimes as "credit" and sometimes as "diploma mobility" students, and sometimes they do not show up in statistics at all.

There is some difficulty in keeping records on the mobility of students, teachers and associates that stem, among other things, from the impossibility of recognizing the category to which a student belong. There is a widespread practice in Europe of reporting the results of statistical analysis on foreign students as an approximation of student mobility (Teichler, 2012). In a study 
on the available statistical basis undertaken in 2006 by the Academic Cooperation Association (ACA), the following problems were stressed (Kelo et al, 2006):

1. International statistics have traditionally provided information about foreign students and study abroad; these data are weak point approximations in terms of student mobility, because a substantial proportion of foreign students in various European countries are not mobile for the purpose of study, but have already lived and been educated in the country of study. On the other hand, some students have lived and learned in another country prior to study and moved to the country of their citizenship for the purpose of study.

2. Many countries include temporary mobile students - i.e. the most frequent mode of intraEuropean student mobility -only partially or not at all in their student statistics. Some countries even count the temporarily outbound mobile student as home students during the study period abroad.

3. The available international statistics do not offer any distinction between 'degree-mobile' or 'diploma-mobile' students, i.e. those intending to study a whole study programme abroad, and 'temporary mobile', 'short-term' or 'credit-mobile' students, i.e. those intending to study abroad for one semester and for a somewhat longer time-span within a study programme.

4. There is no distinction made in the international statistics according to citizenship or mobility according to Bachelor and Master programs.

5. There are no statistics and surveys across Europe suitable for establishing the event of student mobility, i.e. how many students have studied abroad during the course of study either whole study programme or at least some period during the course of study.

By signing the Sorbonne declaration in 1998, ministers in charge of higher education in France, Germany, Italy and the United Kingdom declared that they would establish a 'harmonised' structure of programmes and degrees. On June 1999, 29 European ministers signed the Bologna declaration according to which a structure of programmes and degrees would be established and eventually a European Higher Education Area implemented by the year 2010. According to Teichler (2012) this structural reform and the accompanying measures are called for in the Bologna Declaration as serving the strategic objective aim of contributing to student mobility. Student mobility is seen as a way to overcome the relative isolation of national systems of higher education. Or to reduce obstacles which are created by mobility being affected by the characteristics of individual countries or even different levels of individual countries). Altogether, mobility is seen as an activity than can contribute to structural convergence of higher education systems in the European countries. The final objectives of creating a European Higher Education area would be to increase the attractiveness of higher education in Europe for students from other parts of the world and to facilitate intra-European mobility.

The number of activities were undertaken to support mobility, from which the introducing cyclical study programmes, ECTs and diploma supplement were the most influential.

\section{Historical overview of academic mobility}

Going back to history, mobility is essentially a natural process. Ever since the beginnings of higher education, there have been records of student and teacher mobility. The need for knowledge or the desire for knowledge was the impetus for students moving towards centres of knowledge. The dispersion of knowledge in today's terms was not possible, either for lack of printing technology or the impossibility of transporting written books. At that time, mobility was a dangerous adventure, but life itself was difficult. As the higher education system outgrew the elite and became accessible to a greater number of persons, mobility also acquired a different structure. It gradually became a formal part of the education system. Student academic mobility and its relation to academic performance have been researched since World War II with varying results (Goebel, 1978; referenced by Eddy 2011, p.1). In the late 1980s, acting on behalf of EU member states, the European Commission launched the Erasmus programme that was later integrated into the Lifelong Learning programme. This began the standardisation and structuring of the mobility system. One of the aims of structuring mobility is recognition of achievements during the exchange. 
The core of the idea to establish the European Higher Education Area entailed harmonisation and recognition of higher education systems. According to the Leuven conclusions (2009), by 2020 joint degrees should become a common practice. The cultural development of Europe and a unique whole was accompanied by the development of diverse university systems and structure as a result of innovations, entrepreneurship, intellectual and cultural achievements. The diversity resides in the sphere of structure, curricula, student and teacher interests and ties to the local community, region, state or global environment. Today, there are hundreds of higher education institutions in many countries attended by millions of students, and the common knowledge about which universities were "the best" is no longer available, especially when students wish to pursue an education outside their home country. At the same time, countries that finance these increasingly expensive systems want to know what they are getting for their money and are no longer satisfied with the answer that members of the academic community know their job better and should simply be trusted. It is from this context that the Bologna Declaration came forth and along with it the idea of creating the European Higher Education Area .

Reasons cited in favour of strengthening mobility include innovative global research, an international curriculum, a strong and diverse incentive brought by international students and teachers (Taylor, 2011, p. 2). Mobility is the basis for strengthening so-called "internationalisation at home" (Beelen and Laesk, 2011, p. 2). Internationalisation at Home as a system of international education offers the possibility of finding a new way in which higher education mainstreams the international dimension in all segments of the universities, reforms the curriculum, mobilizes community resources, and institutionalizes international education.

From an institutional standpoint, mobility is an activity of higher education institutions in response to the forces of globalisation- economic, political, cultural and social -that push higher education institutions towards stronger internationalisation. The similarity or heterogeneity of national higher education systems plays an ambivalent role in this case. On the one hand, the diversity of higher education systems is pointed out as an advantage that will enable students to learn and develop reflexive thinking skills and better understand diversity. On the other hand, the Bologna Declaration calls for a structural convergence of higher education systems in Europe so as to, among other things, provide students with an opportunity to move seamlessly through similar systems (Teichler, 2009, p. 7).

Western Balkan countries have signed the Bologna Declaration leads to the creation of the European Higher Education Area. The aim is to increase mobility between institutions of EU member states and third countries. Globally, in 2000, 1.8 million students were studying outside their home countries. It is estimated that by 2025 this number will reach 7.2 million. According to a study by Cheong et al. (2004, p. 4), higher education institutions must monitor the development of the European Higher Education Area and estimate the implications and impact on mobility. Higher education institutions have received financial aid to implement mobility through programmes of support.

\section{Strategic approach to mobility}

According to several studies conducted by then OECD studies (De Wit, 1995 referenced by Gacel-Avila, 2009, p. 7), the implementation of internationalisation strategies largely depends on the establishment and consolidation of structures and functions that are both programedbased and organisational in nature. Both structures are essential and independent of each other. The existence of successful programmes without organisational structures to support their implementation is impossible. Only the existence of both types of structures and functions ensures the viability of internationalisation strategies as has been shown by the experience of advantaged institutions in Canada, in Europe and the Asian Pacific Rim (De Wit, 1995 referenced by Gacel-Avila, 2009, p. 7). As far as organisational structures are concerned, studies conducted on the international dimension of higher education in Latin America (World Bank, 2005, referenced by Gacel- Avila, 2009, p.9) show, among other things, that suitable organisational structures are not sufficiently institutionalised. Among the university central service structures, international offices are the most limited in human resources, and most of them do not have sufficient financial resources, and most of them do not have the financial resources available to run their own programmes. Institutional regulations do not 
exist, leaving the running of international activities marginal to policies and even to the institutional priorities.

According to Moe et al. (2010, p. 69), mobility has become an important segment of international strategies of both countries and higher education institutions. There is a lack of systemic information about the whole mobility picture in Western Balkan countries, especially about the drivers of mobility and the obstacles hindering it, the effects of mobility and about how higher education institutions manage the process of mobility. According to Teichler (2009), higher education institutions differ significantly in terms of the scope of these activities and systemic actions that may be characterised as coherent and targeted policies, or even strategies.

The mobility of students, as an individual phenomenon, has been only partially conceptualized. According to Findlay (2002), the mobility of students is an initial step for one type of skilled labour migration. The mobility of students is a product of globalisation in general (with its increased flow of goods, capital, people and ideas), as well the globalisation of higher education in particular (Altbach and Teichler 2001; Kwiek 2001). This approach is linked to Europeanization and the role of students who speak multiple languages as agents of European integration - new European professionals, or as Favell calls them, "Eurostars" (Favell, 2004; King 2003). The third interpretation links mobility to a "mobility youth culture". According to this theory, going abroad (studying, volunteering) is motivated not so much by traditional economic migration factors (finding a job, better wages), as by the need to experiment.

Among the reasons for increased mobility are innovative global research, international curricula and a strong and varied encouragement from foreign students and staff (Taylor, 2011 1). "Student Mobility in Western Balkan Countries" is a 2009 study, in the form of a research report (Bešić, 2009), with the aim of identifying the perceptions, attitudes and experiences of students from Albania, Bosnia and Herzegovina, Montenegro and Serbia. The study indicates that students from Western Balkan countries find themselves isolated in some sense. The students were questioned during 2008. Since then, there has been the emergence of a meagre number of the student population who have participated in organized and structured mobility via Erasmus Mundus and CEEPUS programs. In their research on the attitude of students at the Faculty of Economics in Split, Dragun and Relja (2006) have established that students have a positive attitude towards mobility, but also that they are not well informed about it. In 2011, a doctoral dissertation was published which dealt with the influence of student mobility on student achievement by surveying a group of students before and after mobility (Eddy, 2011).

Western Balkan countries have signed the Bologna Declaration, which leads to the creation of a European Higher Education Area. The goal is to increase mobility between institutions of European Union member states and institutions outside the European Union. On the global scale, in 2000, 1.8 million students had a study period abroad. It is estimated that by 2025 this number will increase to 7.2 million. According to a study by Cheong et al (2004), institutions of higher education have to oversee the development of the European Higher Education Area and to evaluate its implications and influence on mobility. A program of support provides higher education institutions with financial resources for the realization of mobility.

\section{Methodology}

For the purposes of this research, an electronic survey has been sent to $9 \mathrm{EU}$ and $11 \mathrm{WB}$ universities. Respondents were mainly international relations officers or management representatives. The universities have been selected by their mutual cooperation mainly within the Erasmus Mundus programme. One of the aspect reviewed in this article is representative of internationalisation strategy and policy elements in the internal documents. There is exchange of students, teachers and staff between these universities. At the same time, the universities are members of partnerships for more than one year. The indicators taken into consideration were whether there exist structured documents related to strategy or action plans to foster mobility. Further, did the management of the institution adopted institutional mobility rule-book which will provide guidelines for example, recognition of 
achieving results, how to issue a transcript of records and learning agreement in English, how to register a student in mobility in the registry book etc.

The questionnaire was created by the Public Policy and Management Institute from Lithuania (PPMI) for General Directorate for Education and Culture of the European Commission. It contained questions on general characteristics of HEls regarding mobility documents, international relations offices, the ratio between the number of persons dealing with mobility and total number of students participating in mobility.

\section{Results}

Table 1 shows the data on the number of students participating in mobility and the total number of students in the academic years: $2010 / / 2011$ and $2011 / / 2012$. The University of Lund had almost twice as many incoming students than outgoing students in both academic years. The University of Granada had an equal number of incoming students and outgoing students in the 2010/2011 academic year (2900). The University of Vilnius had almost twice as many outgoing students than incoming students in both academic years. The Karl-Franz University in Graz had an equal number of incoming students and outgoing students in the $2011 / 2012$ academic year (749). The University of Niš had an equal number of incoming students and outgoing students in both academic years (20). The University of Skadar had fewer than five incoming and outgoing students during both academic years. The University of Novi Sad had three times as many outgoing students than incoming students during $2011 / 2012$. The University of Belgrade had almost three times as many incoming students than outgoing students in both academic years.

\section{Table 1}

Number of students participating in mobility (incoming and outgoing) and the total number of students in the academic years: $2010 / / 2011$ and $2011 / / 2012$

\begin{tabular}{|c|c|c|c|c|c|c|}
\hline \multirow[b]{2}{*}{ Institution } & \multicolumn{3}{|c|}{$2010 / 2011$} & \multicolumn{3}{|c|}{$2011 / 2012$} \\
\hline & Incoming & Outgoing & Total & Incoming & Outgoing & Total \\
\hline \multicolumn{7}{|l|}{ EU countries } \\
\hline University of Lund & 1428 & 842 & 40000 & 1796 & 914 & 40000 \\
\hline Masaryk University & $\mathrm{N} / \mathrm{A}$ & $\mathrm{N} / \mathrm{A}$ & $\mathrm{N} / \mathrm{A}$ & 985 & 1188 & 44371 \\
\hline 'Ruprech-Karls' University in Heidelberg & 470 & 650 & 29.000 & 500 & 750 & 30.000 \\
\hline University of Granada & 2900 & 2900 & 79000 & 3200 & 3000 & 80000 \\
\hline University of Gent & 893 & 736 & 35000 & 848 & 837 & 38000 \\
\hline Karl-Franz University in Graz & 776 & 1003 & 28591 & 749 & 749 & 29734 \\
\hline University of Ljubljana & 900 & 1000 & 53608 & 1100 & 1200 & 51859 \\
\hline University of Maribor & 345 & 334 & 18500 & 370 & 360 & 18000 \\
\hline University of Vilnius & 373 & 645 & 22000 & 464 & 690 & 22264 \\
\hline \multicolumn{7}{|l|}{ Western Balkans } \\
\hline University 'Sv. Ćirilo i Metodije', Skopje & 539 & 140 & 36536 & 400 & 160 & 33433 \\
\hline University 'Sv. Kliment Ohridski' in Bitola & 1 & 3 & 12000 & 1 & 10 & 12000 \\
\hline University of Banja Luka & 8 & 5 & 17000 & 1 & 11 & 17000 \\
\hline University of Belgrade & 1701 & 650 & 80000 & 1750 & 640 & 80000 \\
\hline University of Montenegro & 65 & 165 & 21000 & 28 & 153 & 22000 \\
\hline University of Niš & 20 & 20 & 15000 & 20 & 20 & 15000 \\
\hline University of Novi Sad & 29 & 56 & 47100 & 51 & 154 & 47800 \\
\hline Univerzitet u Sarajevu & 20 & 51 & 35000 & 40 & 83 & 32000 \\
\hline Univerzitet u Skadru & 3 & 4 & 12300 & 3 & 2 & 13000 \\
\hline University of Split & 45 & 68 & 23.000 & 45 & 150 & 23.000 \\
\hline University of Zagreb & 214 & 365 & 76946 & 326 & 639 & 70000 \\
\hline
\end{tabular}

Note: N/A - data not available

Source: Own research conducted with a sample of institutions in June 2012.

Table 2 shows descriptive statistics on number of students participating in mobility and the total number of students in the academic years: $2010 / / 2011$ and $2011 / / 2012$. Average number of incoming students in EU based universities was 1010,63 in 2010/2011, and it increased to 1112,44 in 2011/212. Average number of outgoing students from EU based 
universities was 1013,75 in 2010/2011 and it also increased to 1076,44 in 2011/12. On the other side, Western Balkans based universities had much lower number of incoming and outgoing students. Average number of incoming students in Western Balkans based universities was 240,45 in 2010/2011 and it remained almost the same in 2011/2012. Average number of outgoing students in Western Balkans based universities was 138,82 in 2010/2011 and it increased to 183,82 in 2011/2012. In the same time, total number of students is similar in EU and Western Balkans based universities.

Table 2

Descriptive statistics on number of students participating in mobility and the total number of students in the academic years: $2010 / / 2011$ and $2011 / / 2012$

\begin{tabular}{|c|c|c|c|c|c|c|c|}
\hline \multirow[b]{2}{*}{ Region } & \multirow[b]{2}{*}{ Indicators } & \multicolumn{3}{|c|}{ 2010/2011 } & \multicolumn{3}{|c|}{$2011 / 2012$} \\
\hline & & Incoming & Outgoing & Total & Incoming & Outgoing & Total \\
\hline \multirow[b]{3}{*}{ EU } & Mean & 1010,63 & 1013,75 & 38212,38 & 1112,44 & 1076,44 & 39358,67 \\
\hline & $\mathrm{N}$ & 8 & 8 & 8 & 9 & 9 & 9 \\
\hline & Std. Dev. & 842,357 & 792,396 & 19795,483 & 893,752 & 765,500 & 18587,618 \\
\hline \multirow{3}{*}{$\begin{array}{l}\text { Western } \\
\text { Balkans }\end{array}$} & Mean & 240,45 & 138,82 & 32808,82 & 242,27 & 183,82 & 31840,73 \\
\hline & $\mathrm{N}$ & 11 & 11 & 11 & 11 & 11 & 11 \\
\hline & Std. Dev. & 510,067 & 200,346 & 26101,077 & 518,704 & 234,303 & 24878,615 \\
\hline \multirow[b]{3}{*}{ Total } & Mean & 564,74 & 507,21 & 35084,00 & 633,85 & 585,50 & 35223,80 \\
\hline & $\mathrm{N}$ & 19 & 19 & 19 & 20 & 20 & 20 \\
\hline & Std. Dev. & 757,038 & 680,773 & 23203,119 & 821,713 & 695,132 & 22044,479 \\
\hline
\end{tabular}

Source: Own research conducted on a sample of institutions in June 2012.

Table 3 gives the data on the existence of rules on mobility in institutions from the sample classified by region. There are twice as many institutions in Western Balkan countries without rules on mobility (6) than among the institutions from EU countries (3). The number of institutions with rules on mobility is almost the same for EU countries (6) and Western Balkan countries (5).

Table 3

Existence of rules on mobility in institutions from the sample by region

\begin{tabular}{|l|r|r|r|}
\hline Existence of rules on mobility & EU & Western Balkans & Total \\
\hline No rules on mobility & 3 & 6 & 9 \\
\hline Rules on mobility exist & 6 & 5 & 11 \\
\hline Total & 9 & 11 & 20 \\
\hline
\end{tabular}

Source: Own research conducted on a sample of institutions in June 2012.

The Hypothesis of this research is that the degree of representation of internationalisation strategy and policy elements in the internal documents of a higher education institution has a direct impact on the development of mobility. Accordingly, (1) the degree of representation of internationalisation strategy and policy elements in the internal documents of a higher education institution is measured by the existence of Rules on Mobility within the institution, and (2) the development of mobility is measured by the proportion of incoming students and outgoing students in the total number of students expressed as percentage values.

In order to test this hypothesis mean values of the proportion of incoming and outgoing students in the total number of students expressed as percentages and in relation to the existence of rules on mobility within the institution (Table 4). These values were calculated for the 2010/2011 and 2011/2012 academic years. It was shown that institutions with rules on mobility achieve a higher percentage of incoming and outgoing students for both academic years. For example, institutions with the Rules on Mobility in had on average $1.86 \%$ incoming students in $2011 / 2012$, while institutions without rules on mobility had on average $0.83 \%$ incoming students in the same academic year. 


\section{Table 4}

Descriptive statistics on \% of incoming and outgoing students at institutions from the sample in relation to the existence of rules on mobility within the institution: academic years: $2010 / / 2011$ and $2011 / / 2012$

\begin{tabular}{|l|l|r|r|r|r|}
\hline \multirow{2}{*}{$\begin{array}{l}\text { Existence of rules on mobility } \\
\text { within an institution }\end{array}$} & & \multicolumn{2}{|c|}{$2010 / 2011$} & \multicolumn{2}{|c|}{$2011 / 2012$} \\
\hline \multirow{4}{*}{$\begin{array}{l}\text { Rules on mobility exist in an } \\
\text { institution }\end{array}$} & Mean & $1,65 \%$ & $1,65 \%$ & $1,86 \%$ & $1,79 \%$ \\
\hline \multirow{4}{*}{$\begin{array}{l}\text { Rules on mobility do not exist } \\
\text { in an institution }\end{array}$} & No.of institutions & 10 & 10 & 11 & 11 \\
\cline { 2 - 6 } & St.dev. & $1,39 \%$ & $1,35 \%$ & $1,52 \%$ & $1,16 \%$ \\
\cline { 2 - 6 } & Mean & $0,84 \%$ & $0,77 \%$ & $0,83 \%$ & $0,89 \%$ \\
\cline { 2 - 6 } & No.of institutions & 9 & 9 & 9 & 9 \\
\cline { 2 - 6 } & St.dev. & $0,98 \%$ & $0,98 \%$ & $0,97 \%$ & $1,09 \%$ \\
\hline \multirow{3}{*}{\begin{tabular}{l} 
Total \\
\hline
\end{tabular}} & Mean & $1,27 \%$ & $1,24 \%$ & $1,40 \%$ & $1,39 \%$ \\
\cline { 2 - 6 } & No.of institutions & 19 & 19 & 20 & 20 \\
\cline { 2 - 6 } & St.dev. & $1,25 \%$ & $1,24 \%$ & $1,37 \%$ & $1,19 \%$ \\
\hline
\end{tabular}

Source: Own research conducted on a sample of institutions in June 2012.

In order to test the paper hypothesis, a Mann-Whitney non-parametric test was conducted (Table 5). The test results showed there is a statistically significant difference in the following data: (i) percentage of incoming students in 2010/2011 with 5\% probability (Mann-Whitney $\mathrm{U}=20,000$; $\mathrm{p}$-value $=0,043$ ); (ii) percentage of outgoing students in 2010/2011 with 10\% probability (Mann-Whitney $U=23,000 ; p$-value $=0,079$ ); (iii) Percentage of incoming students in $2011 / 2012$ with $10 \%$ probability (Mann-Whitney $U=25,000 ; p$-value $=0,067$ ), and (iv) Percentage of outgoing students in 2011/2012 with 5\% probability (Mann-Whitney $U=21,000$; $p$ value $=0,031$ )

Table 5

Mann-Whitney test for the difference in \% of incoming and outgoing students at institutions from the sample in relation to the existence of rules on mobility within the institution

\begin{tabular}{|l|l|r|r|}
\hline Academic year & Development of mobility & Mann-Whitney U & P-value \\
\hline \multirow{3}{*}{$2010 / 2011$} & \% Incoming & 20,000 & $0,043^{* *}$ \\
\cline { 2 - 4 } & \% Outgoing & 23,000 & $0,079^{*}$ \\
\hline \multirow{3}{*}{$2011 / 2012}$. & \% Incoming & 25,000 & $0,067^{*}$ \\
\cline { 2 - 4 } & \% Outgoing & 21,000 & $0,031^{* *}$ \\
\hline
\end{tabular}

Note: *statistically significant with $10 \%$ probability; ${ }^{* *}$ statistically significant with $5 \%$ probability Source: Own research conducted on a sample of institutions in June 2012.

Based on the conducted Mann-Whitney non-parametric tests, we can conclude that the hypothesis about the representation of internationalisation strategy and policy elements in internal documents of a higher education institution having a direct impact on the development of mobility has been confirmed. In other words, degree of representation of internationalisation strategy and policy elements in the internal documents of a higher education institution has a direct impact on the development of mobility.

\section{Discussion and conclusion}

Mobility is among the strategic priorities in a number of documents issued by the joint meeting of Bologna countries at different levels.

According to the last Bucharest Communiqué, adopted at the Ministerial Conference held in Bucharest in April 2012, "HE structures in Europe are now more compatible and comparable. Student today benefit from a wider variety of educational opportunities and are increasingly mobile. The vision of an integrated EHEA is within reach". This is a conclusion of the ministerial conference, while the voice of the academic community was not present there. According to a study of the Bologna Process in the Tempus Partner Countries (EACEA, 2012)reforming higher education in the Western Balkans is a long process and conditions are not always favourable to change due to past heritage and local political context. The technical and administrative staff provides support for academic and other activities of HEls 
and are assigned to various duties in the academic and service units where they report to the relevant heads of these units (NiiBoeTagoe, 2012, p.40). It is questionable if there is an adequate response in a number of staff in most Western Balkans institutions allocated for such activities whose duties are at the same time unclear due to lack of strategic documents.

Higher education institutions are undergoing a change in management culture where more and more management responsibilities in higher education are relegated to the fulltime administrative staff of higher education institutions. This means that traditional forms of administration need to be adapted and developed to approximate management in its true form (Pellert, 2012). According to Tempus study on HRM in Public HE in the Tempus partner Countries (Dubosc\&Kelo, Issue 10, June 2012, p. 95), in the Western Balkans, the main issue reported in the national questionnaire in terms of academic staff were their lack of flexibility and resistance to change, unwillingness to implement changes is also one of the most frequently mentioned weaknesses. The questionnaire for Bosnia and Herzegovina expressed a concern for the lack of experienced academic staff, which would at the same time be open to change. In other words, young staff may be more open to change, but lack the needed experience. Lack of team working skills was also reported. The same study reported far too little attention given to the recruitment requirements, skills, motivation and training of administrative and technical staff (Dubosc and Kelo, 2012). According to this study, administrative and technical staff is considered far removed from the core operations of institutions while at the same time, administrative and technical staff can play an important role in the modernization of institutions and for well performing of all activities at a national and international level. Similarly, Neely argues that appropriate performance indicators encourage employees to act in alignment with the strategic goals (Neely, 1999, Drobne et al., 2012). The research can add some light to multi-faceted context of academic mobility. In order to contribute to the overall understanding of a variety of complex issues the wider research is required, among students and their perceptions, and between the academic community and ministerial community, as the latter are adopting and creating important documents imposing changes in higher educational systems.

Higher education institutions in Western Balkan countries have traditionally been open to cooperation. Academic mobility, by its nature and use of resources, is a basis for active participation in the European Higher Education Area, as well as for the overall strengthening of the international dimension of all segments of the university, the reform of study programs, the mobilisation of resources in the immediate and wider community and the institutionalization of the international aspect of local education. At the same time, there is a lack of systematic knowledge in a given area in the Western Balkans. Therefore further research should further analyse the state of play in the segment of management and governance within higher education in the Western Balkan, such as try to shed more light into lack of statistical data for academic mobility. For higher education institutions in Western Balkan countries, this new type of mobility-structured mobility-is an important influence on the academic community, not only in the sense of research and didactic structures, but also in the sense of developing support systems. It is necessary to increase the degree of representation of internationalisation strategy and policy elements in the internal documents of a higher education institutions to achieve a direct impact on the development of mobility. Applying the Bologna principles has encouraged the growth of a culture of change and has developed differences not only between countries, but also among higher education institutions within the same country. Creating the European Higher Education Area is becoming a real and difficult challenge. The task is in no way simple, mostly because of the complexity of the various national systems and their different histories. An important goal in creating this space is maintained and supporting the diversity of educational systems.

The limitation of this research regarding the relatively small number of respondents and limited timeframe should be taken into account when using its results as the basis for future decisions. However, some recommendation emerged for future research of academic mobility in WB, such as to: (i) explore the nature of internationalisation of higher education institutions, (ii) explores communication channels between ministries and representatives of the academic community, and (iii) explore communication between representatives of the academic community and the administration. This information would give more insight on 
leverages for increasing mobility between EU and WB countries, which has an important role in the holistic development of the European.

\section{References}

1. Altbach, P.G., Teichler, U. (2001), "Internationalisation and exchanges in globalised university", Journal of Studies in International Education, Vol. 5, No. 1, pp. 5-25

2. Beelen, J., Leask, B. (2011), "Internationalisation at Home on the Move", in Bergan, S., Egron-Polak, E., Koher, J., Purser, L., and Spyropoulou, A. (Ed). Internationalisation of European Higher Education: Learning \& Teaching, Berlin: Raabe Academic, Supplement.

3. Bešić, M. (2009), "Student Mobility in Western Balkan countries", Research Report, King Baudouin Foundation, Brussels;

4. Cheong, J. et al (2004), "International student mobility", Issues paper. July 2004/30. Sussex Centre for Migration Research, university of Sussex, Sussex.

5. Communiqué of the Conference of European Ministers Responsible for Higher Education, EHEA Ministerial Conference, Bucharest 2012, Romania, available at: http://www.bfug.eu /(September 12, 2012)

6. Communiqué of the Conference of European Ministers Responsible for Higher Education, Leuven and Louvain-la-Neuve, available at: http://www.enqa.eu / (110 Apri, 2009)

7. De Witt, H.,(2012), "International Student Circulation in the Global market", in Bergan, S., Egron-Polak, E., Koher, J., Purser, L., and Spyropoulou, A. (Ed). Internationalisation of European Higher Education: Learning \& Teaching, Berlin: Raabe Academic, Supplement.

8. Dragun, A, Relja, R. (2006). "Akademska mobilnost studenata: Stavovi studenata Ekonomskog fakulteta u Splitu", Revija za sociologiju,. Vol XXXVII., No.1-2, pp. 63-76.

9. Dubosc, F., Kelo, M., (2012), "Human Resource Management in Public Higher Education in the Tempus partner Countries", A Tempus Study number 10, June 2012, EACEA, Brussels.

10. Drobne, S., Bogataj, M., Lisec, A. (2012). "Dynamics and local policy in labour commuting", Business Systems Research, Vol. 3, No. 2, pp. 14-26.

11. Eddy, L. (2011), "The Effect of Student Mobility on Student Achievement, Doctoral Dissertation" University of Kentucky, available at http://uknowledge.euky.edu/gradschool_diss/177 / (12 October, 2011)

12. Education, Audovisual and Culure Executive Agency, „Human Resource Management in Public Higher Education in the Tempus Partner Countries", No. 10, June 2012, EACEA, Brussels

13. Education, Audovisual and Culure Executive Agency,(2012), "State of Play of the Bologna Process in the Tempus partner Countries", No.09, EACEA, Brussels, April 2012

14. Findlay, A. (2002), "From Brain Exchange to Brain Gain: Policy Implication for the UK of Recent Trends in Skilled Migration from Developing Countries", International Migrations, papers 43, 13. February 2002,

15. Gacel-Avila, J. (2009), "Internationalisation in Latin American Higher Education: main challenges, debates, and trends", in Bergan, S., Egron-Polak, E., Koher, J., Purser, L., and Spyropoulou, A. (Ed). Internationalisation of European Higher Education: Learning \& Teaching, Berlin: Raabe Academic, Supplement.

16. Goebel, B.L. (1978), "Mobility and education", American Secondary Education, Vol. 8 , No. 4, available at:

http://eacea.ec.europa.eu/education/eurydice/documents/thematic_reports/138EN.p df / (September 12, 2011)

17. Kello, M.,Teichler,U. and Waechter, B., (2006), "Students Mobility in European Higher Education", EURODATA, Academic Cooperation Association (ACA), Bonn.

18. Kwiek, M. (2001), "Higher Education in Europe", Globalisation and Higher Education, Vol. 26, pp 27-38.

19. Leuven/Louvain-la-Neuve Communique", 2009, Leuven, (April 12 2009).

20. Nii Boi Tagoe, C. (2012), "Styles and Tools of Leadership in Higher Education“, in Bergan, S., Egron-Polak, E., Koher, J., Purser, L., and Spyropoulou, A. (Ed). Internationalisation of European Higher Education: Learning \& Teaching, Berlin: Raabe Academic, Supplement. 
21. Pellert, A. (2012). "Academic leadership. Structures, Processes and Culture“, in Bergan, S., Egron-Polak, E., Koher, J., Purser, L., and Spyropoulou, A. (Ed). Internationalisation of European Higher Education: Learning \& Teaching, Berlin: Raabe Academic, Supplement.

22. Saarikallio-Torp, M., Wiers-Jenssen, J. (2010). Student mobility patterns, student support systems and labour market outcomes, available at

https://helda.helsinki.fi/bitstream/handle/10138/17453/Tutkimuksial 10.pdf? sequenc.. / (January, 2012)

23. Škrinjar, R., Bosilj Vukšić, V., Indihar Štemberger, M. (2010), "Adoption of Business Process Orientation Practices: Slovenian and Croatian Survey", Business Systems Research, Vol. 1 No.1-2, pp.5-19.

24. Taylor, J. (2011), The management of Internationalisation in Higher Education. Some UK Examples of Strategy and Practice. In: Liempd, H.G. (Ed.) Internationalisation of European Higher Education: Implementation and management. Berlin: Raabe Academic, Supplement.

25. Teichler, U. (2009), "The Internationalisation of European Higher Education: Debates, Policies, Trends", in: Gaebel, M. (Ed.) Internationalisation of Higher Education: Definitions and driving forces for internationalisation. Berlin: Raabe Academic, Supplement.

26. Teichler, U.,(2012), International Student Mobility and the Bologna Process. Research in Comparative \& International education. Volume 7 Number 1, 2012, available at: www.wwwords.uk/RCIE / November 13, 2012

\section{About the authors}

Jasna Bošnjović is a PhD candidate at School of Economics and Business, University of Sarajevo, Bosnia and Herzegovina. Main research interests are Management in Higher Education, Business Processes, Human Resource Management and Communicology. Author can be contacted at jasna.bosnjovic@unsa.ba

Veljko Trivun is full-time professor at School of Economics and Business, acted as Vice Rector of the University of Sarajevo in the period 2006-2008 and Dean of the School of Economics and Business in the period 2008-2012. Areas of expertise: Business Law, International Business Law, Corporate Governance, Corporate Law, Privatization, Public Private Partnership, Elegislation. Author can be contacted at: veljko.trivun@efsa.unsa.ba 